\title{
A DINÂMICA ESTRUTURAL DO CAMPO RELIGIOSO: ALGUNS DADOS EMPÍRICOS
}

Julieta Beatriz Ramos Desaulniers*

SINTESE - Este artigo constitui um esforço no sentido de articular teoria, método e dados, quando procura expor alguns resultados sobre as pesquisas desenvolvidas junto a escolas de ofício católicas de Porto Alegre/RS, que têm no referencial de Pierre Bourdieu um dos seus principais referenciais teóricos.
ABSTRACT - This article consists of an effort towards articulating theory, method and data, while seeking to display some results on research carried out in catholic vocational schools of Porto Alegre, Rio Grande do Sul, which have in Pierre Bourdieu one of their main theoretical foundations.

A abordagem de Pierre Bourdieu constitui uma referência importante para captar os mecanismos e relações que configuram o processo de formação instaurado junto às escolas de ofício católicas, situadas em Porto Alegre/RS, no período de 1895 a 1970, as quais integram a dinâmica do campo religioso. ${ }^{1}$

\section{1 - Considerações sobre o referencial teórico de Pierre Bourdieu}

Aos diversos "mundos", relativamente autônomos, que compõem uma sociedade, Bourdieu atribui a denominação de campo. ${ }^{2}$ Entende-se que essa noção e a de grupos sociais se referem à estrutura social, e as associa também ao conceito de classes sociais. $^{3}$

A noção de campo - central nessa abordagem - serviu, inicialmente, "para indicar uma direção à pesquisa". ${ }^{4}$ Em certo sentido, essa noção "é uma estenografia

- Pontificia Universidade Católica do Rio Grande do Sul, PUCRS.

1 O referido fenômeno vem sendo pesquisado a partir de vários sub-projetos que estão articulados à sub-linha de pesquisa "Formação, Trabalho, Instituição", bem como ao Projeto Integrado "Urbanidade e cidadania: processos de formação e de instauração de saberes, séc. XX/RS", o qual conta com o financiamento do CNPq e da FAPERGS. Alguns trechos desse item foram extraidos da Tese de Doutorado "Trabalho: a escola do Trabalhador?", defendida em maio/93, junto ao PPGRAD em Educação/UFRGS Porto Alegre/RS/Brasil, p. 47 a 52. BOURDIEU, Pierre. Coisas Ditas. São Paulo. Ed. Brasiliense, 1990, p. 93.

3 Idem, p. 149.

4 BOURDIEU, Pierre. O poder simbólico. Lisboa, Editora Difel, 1989, p. 64.

\begin{tabular}{|l|l|l|l|l|l|}
\hline VERITAS & Porto Alegre & v. 41 & $\mathrm{n}^{\circ} 162$ & Junho 1996 & p. 249-260
\end{tabular}


conceitual de um modo de construção do objeto que vai comandar - ou orientar todas as opções práticas da pesquisa". ${ }^{5}$

Com o tempo, foi sendo elaborada a teoria geral da economia dos campos, a qual "permite descrever e definir a forma específica de que se revestem, em cada campo, os mecanismos e os conceitos mais gerais" ${ }^{\prime 6}$... Obtém-se a análise da essência do campo, através da análise da história do campo. ${ }^{7} \mathrm{E}$, assim, apreende-se a particularidade na generalidade e a generalidade na particularidade. ${ }^{8}$

$\mathrm{O}$ autor define campo como um "sistema de desvios de niveis diferentes e nada, nem nas instituições ou nos agentes, nem nos atos ou nos discursos que eles produzem, tem sentido senão relacionalmente, por meio do jogo das oposições e das distinções". ${ }^{9}$

Em outros termos, o campo "constitui-se de forças, variando de acordo com as posições que os agentes ocupam e lutas de concorrência que tendem a conservar ou transformar o campo de forças" ${ }^{10} \mathrm{E}$ a luta entre os agentes que faz a história do campo, ${ }^{11}$ sendo este, aliás, o próprio "lugar de lutas". ${ }^{12}$

Diz o autor que "a análise das estruturas objetivas - as estruturas dos diferentes campos - é inseparável da gênese, nos indivíduos biológicos, das estruturas mentais e da análise da gênese das próprias estruturas sociais: o espaço social, bem como os grupos que nele se distribuem são produtos de lutas históricas" ${ }^{13}$

Bourdieu propõe o modelo da relação entre os campos e os habitus - sistema de disposições adquiridas na relação com um determinado campo - fornecendo, assim, a "única maneira rigorosa de reintroduzir os agentes singulares e suas ações singulares", sem incorrer na história factual. ${ }^{14}$.

Porém, são as disposições dos indivíduos que mediatizam as posições e as tomadas de posição dos agentes. Assim, mesmo sendo bastante significativo o efeito do campo sobre os agentes, ele não se exerce mecanicamente. ${ }^{15}$

Observa-se, todavia, que "a relação entre habitus e campo é, em primeiro lugar, uma relação de condicionamento em que o campo estrutura o habitus, que é produto da necessidade imanente" deste ou de outros campos concordantes. É também uma relação de conhecimento ou construção cognitiva. Por isso, na relação entre habitus e campo, "a história entra em relação com ela mesma: é uma verdadeira cumplicidade ontológica que une o agente e o mundo social" ${ }^{16}$

\footnotetext{
Idem, p. 27.

Idem, p. 69.

Idem, p. 71.

BOURDIEU, op. cit., p. 171 (1990).

BOURDIEU, op. cit., p. 179 (1989).

10 BOURDIEU, Pierre. "Le Champ littéraire". In: Revue Actes de la Recherche en Sciences Sociales. Paris. Editions de Minuit, $n^{2} 89$, sept/1991, p. 5. (Trad. da autora).

11 Idem, p. 24.

12 BOURDIEU, op. cit., p. 172 (1990).

13 Idem, p. 26 (1990).

14 Idem, p. 63.

15 BOURDIEU, op. cit., p. 42 (1991). (Trad. da autora).

16 BOURDIEU, Pierre. Réponses - pour une anthropologie réflexive. Paris, Editions du Seuil. 1992, p. 103. (Trad. da autora).
} 
Vários são os elementos que compõem a noção de habitus, os quais são produzidos pelos condicionamentos, associados a uma classe particular de condições de existência. É definido como "sistema de disposições duráveis e transponiveis, estruturas estruturadas, predispostas a funcionar como estruturas estruturantes. ${ }^{17}$

É importante notar que nem tudo no mundo, nem todas as disposições farão parte do habitus de uma pessoa. Suas experiências passadas exercerão um papel de filtro, e só as que forem mais compativeis com seu habitus serão assimiladas. ${ }^{18}$

O habitus exprime sempre a posição social em que foi constituido, tanto na condição de um sistema de esquemas de produção de práticas, quanto, ao mesmo tempo, na condição de um sistema de esquemas de percepção e apreciação das práticas. $^{19}$

A incorporação do habitus ocorre por meio de "uma ação pedagógica que visa inculcar, o mais profundamente possivel, o mais durável possível, através de comportamentos precisos, singulares, uma atitude. Ou seja, um certo tipo de relação global consigo mesmo e com as coisas, com a vida e com o mundo". ${ }^{20}$

A constituição do habitus, que resulta nas propriedades dos ocupantes das posições, vai dèpender de várias circunstâncias do próprio campo: sua autonomia, posição ocupada pelo agente no campo e o grau de institucionalização do posto ou posição correspondente.

Mesmo que o habitus não seja imutável ${ }^{21}$ - é uma estrutura sempre em vias de reestruturação, já que as experiências acumulam saberes ${ }^{22}$ - enquanto sistema de disposições para a prática, constitui o fundamental objetivo de condutas regulares. É por isso que é possivel obter regularidade de condutas e prever as práticas: "o habitus faz com que os agentes que o possuem comportem-se de uma determinada maneira em determinadas circunstâncias". ${ }^{23}$

Assim, enquanto produto da história, os habitus produzem práticas individuais e coletivas, que garantem a presença das experiências passadas, como também, através dos tempos, "a conformidade das práticas e a sua constância". Em função de seus limites, consignados às suas invenções, é que a estrutura governa a práti$\mathrm{ca}^{24}$

Em síntese, conforme Heran, o habitus:

- é um saber que se tem à mão;

- habita a alma, assim como a roupa habita o corpo;

- é algo poderosamente gerador;

- ativa o passivo e atualiza o passado;

- engloba os resultados e o processo;

17 BOURDIEU, Pierre. Le sens pratique. Paris. Les Editions de Minuit. 1980, p. 88. (Trad. da autora).

18 Idem, p. 89.

19 BOURDIEU, op. cit., p. 158. (Trad. da autora).

20 ACCARDO, Alain. Initiation à la Sociologie. Bordeaux, Editions Le Marcaret, 1983, p. 141. (Trad. da autora).

21 BOURDIEU, op. cit., p. 109 (1992). (Trad. da autora).

22 ACCARDO, op. cit., p. 146. (Trad. da autora).

23 BOURDIEU, op. cit., p. 98 e 26 (1990).

24 BOURDIEU, op. cit., p. 91 (1980). (Trad. da autora). 
- é produto das práticas individuais e coletivas e, assim, é produto da história;

- é uma forma particular de capital;

- ocupa várias regiōes da prática;

- é a interiorização do exterior e a exteriorização da interioridade;

- possibilita ser e ter sido. ${ }^{25}$

Assim, utiliza-se esse referencial tanto para analisar o processo de formação instaurado no PÃO DOS POBRES - um processo totalizante e propício à produção de um novo habitus junto ao interno órfão - como para captar o sistema de relações construido nesse mesmo processo, e que é representado pela dinâmica estrutural do campo religioso, em confronto com os demais campos do poder.

\section{2 - O campo religioso e a formação de trabalhadores}

Pretende-se destacar como a ocupação controlada do tempo e do espaço constituiram-se numa das principais estratégias do processo de formação de futuros trabalhadores, que foi instaurado em escolas de ofício católicas dirigidas por diversas congregações religiosas, a partir do final do século XIX. ${ }^{26}$

O grande objetivo desse empreendimento era o de "formar o homem todo para, assim, produzir um novo homem, útil a si e à sociedade". Isso supunha a utilização de um conjunto de estratégias, capazes de instaurar uma ruptura no habitus dos alunos que ingressavam em tais escolas, a fim de garantir as possibilidades de se produzir a forma que esse processo educativo pretendia alcançar.

Os estudos realizados desde $1988 \mathrm{com}$ o intuito de reconstituir tal dinâmica (com base em diversas fontes primárias como documentos, fotografia, material pedagógico, depoimentos, etc.), indicam a PIA UNIÃO DO PÃO DOS POBRES, fundada em Porto Alegre/RS/Brasil, em 1895, pelo Cônego Marcelino Bittencourt, como o caso exemplar dentre as demais escolas de ofício católicas. Por isso, os cọmentários a serem apresentados dizem respeito, especialmente, a essa instituição.

Sem dúvida, foi nessa entidade que os postulados do novo discurso religioso desencadeado em 1891, com a publicação da Encíclica Rerum Novarum, foram reinterpretados de modo mais radical e verticalizado, através da pedagogia aplicada pelos Irmãos Lassalistas - os representantes da Igreja católica - que assumiram o PÃO DOS POBRES, após 1916.

Até 1930, as bases institucionais estavam adequadas para o pleno desenvolvimento desse tipo de formação que recorreu ao regime de internato fechado para órfãos pobres, utilizando modalidades religiosas, disciplinares e práticas técnicas, com os tempos prévia e rigorosamente definidos e os espaços visivelmente demarcados pelos limites dos muros e dos prédios, assim como pelas inúmeras atividades que o interno era obrigado a realizar durante todo o dia.

25 HERAN, François. "La seconde nature de l'habitus - tradition philosophique et sens commun dans le langage sociologique". In: Revue Française de Sociologie. Juillet/Sept n² XXVIII - 3, 1087, p. 385413. (Trad. da autora).

26 As considerações apresentadas a seguir referem-se a conteúdos abordados na Tese de Doutorado, op. cit., os quais foram expostos no XVI Congresso Intemacional de História da Educação (ISCHE), em Amsterdã/Holanda - Agosto/94 e na XVII Reunião Anual da Associação Nacional de Pós-Graduação em Educação (ANPEd), em Caxambu/MǴ - outubro/94. 
Com esse conjunto de dispositivos, garantido por uma supervisão austera dos Irmãos que aumentavam a cada ano, a formação realizada em escola de ofício católica diferencia-se significativamente dos demais processos voltados às classes populares. A sua trajetória esteve sempre articulada à dinâmica capital-trabalho constituída nas bases de um poder elitista e é possível afirmar, a partir da realidade vivida pelos ex-alunos do internato, que tal ação educativa foi capaz de, através da gama de saberes, instaurar alguma competência ("saber-ser") junto aos seus formados.

\section{1 - Alguns aspectos da formação no Pão dos Pobres: uma escola de ofício católica}

As práticas pedagógicas utilizadas pela entidade católica - A PIA UNIÃO DO PÃO DOS POBRES de SANTO ANTÔNIO - baseavam-se num sistema de relações fortemente hierarquizado, o que garantia a estruturação de um novo habitus, pelo qual se operacionalizava o objetivo último do novo discurso: formar o homem integral, enraizado na força divina e capaz de servir a si e à Pátria. ${ }^{27}$

Após 1930, a rotina continuava praticamente a mesma dos primeiros tempos do ORFANOTRÓFIO, porém incluía maior diversidade e quantidade de tarefas a serem realizadas pelos internos num ritmo muito mais intenso, com o tempo e o espaço austeramente controlados pelos Irmãos.

Ao se referir à rotina do Orfanato, um dos ex-internos lembra:

Acordava às 6 horas com o Irmão tocando a campainha. Rezava ao pé da cama e depois ia me lavar; no próprio dormitório havia pias. Depois de arrumar a cama descia em fila para a capela onde assistia à missa (6h30min às $7 \mathrm{~h} 30 \mathrm{~min}$ ). Depois, novamente em fila, dirigia-se para o refeitório para tomar café; isso durava uns quinze minutos mais ou menos. Em seguida, cada menino se dirigia para o seu serviço de limpeza (lavar banheiros, varrer os corredores, etc). Às $8 \mathrm{~h}$, todo mundo ficava em fila em frente às salas de aula para dar início aos estudos. Eram mais ou menos duas horas de aula, depois tinha o recreio. Mas a aula era a manhã toda para a turma dos menores (a turma dos maiores de 14 a 18 anos, ficava na oficina $o$ dia todo). Depois vinha o almoço e um recreio de uma hora. Em seguida reiniciavam as aulas. À tarde faziam os temas também. Tinha aulas de desenho, de canto, de geografia, até as 17 horas. A catequese era dada na parte da manhã, a última hora antes do almoço, quando a turma já estava um pouco cansada.

Às $17 \mathrm{~h} 30 \mathrm{~min}$, mais ou menos, todos se reuniam numa sala grande, chamavam de estudo geral. Todos faziam os temas supervisionados pelo prefeito. Às $19 \mathrm{hs}$ tinha a janta. Até as $20 \mathrm{~h}$ tinha um recreio no pátio, hora em que os menores subiam para dormir. Os maiores iam para uma sala que chamavam de estúdio: lá se fazia temas e escutava-se rádio.

Todos esses tempos, vividos em vários espaços do internato, repletos de ações e movimentos, tinham seus ritmos próprios e eram vividos pelo órfão na sua posi-

27 Conforme pensamento de Jean-Baptista de La Salle. In: JUSTO, E. Henrique, La Salle, patrono do magistério - vida, biografia, pensamento, obra pedagógica. Porto Alegre, Livraria Santo Antônio, 1961, p. 35. 
ção de subordinado frente a Deus. Nos momentos de oração (na missa, na catequese, nas preces, antes e depois de cada atividade) tanto o interno como o Irmão situavam-se na mesma posição, voltados para a transcendência. Já nos ritmos do dormitório, do refeitório, da sala de aula, das oficinas e das atividades de lazer, o órfão ficava subordinado a Deus, ao Irmão, ao mestre, ao colega mais velho. Exercia-se assim sobre ele uma dupla pedagogia: a de Deus, que "ensinava" aos Irmãos, e a destes, responsáveis diretos pela educação dos internos.

O modo de comportar-se durante todo o tempo, em cada uma das atividades da rotina, estava previsto em um Regulamento implantado em 1927, que passou a vigorar, com mais intensidade, após 1930. O seu primeiro artigo estabelecia que "agasalhados exclusivamente por caridade, os órfãos deverão tratar sempre com muito respeito e grande veneração aos seus superiores".

Assim, ao se estipular a posição a ser ocupada pelo interno no espaço do ORFANOTRÓFIO, determinava-se também o contexto (o ambiente, o clima, o lugar) ${ }^{2 B}$ em que seriam vividos os vários tempos, os quais passariam a fazer parte da história do órfão, reconstruida e construída no interior desse novo espaço.

Foram esses os componentes que definiram e, ao mesmo tempo, diferenciaram a forma do trabalhador "gestada" pelo PÃO DOS POBRES, em relação a outros processos instaurados em escolas de ofício não católicas ou mesmo católicas, em Porto Alegre, no período considerado nesse estudo (1930 a 1970), os quais estavam estreitamente associados com a utilização controlada do tempo e do espaço dos seus formandos.

Nesse sentido, a estrutura e o funcionamento do PÃO DOS POBRES apresentaram muitos pontos semelhantes ao que Goffman denomina de instituições totais. $^{29}$

É certo que as experiências passadas do órfão interno exerciam influência, no sentido de facilitar ou de impor resistências à incorporação de valores e comportamentos mais ou menos compatíveis com o seu habitus anterior ao ingresso no Orfanato. No entanto, foi esse ambiente, permeado de austeros princípios, que provocou a ruptura daquelas disposições adquiridas até aquele momento, e a instauração de um novo habitus, construído durante sua permanência no Orfanato, como um produto da cumplicidade entre esse espaço e o interno. ${ }^{30}$

As considerações de um dos Irmãos entrevistados referem-se a estratégias empregadas para a instauração de um novo habitus no interno:

[...] a disciplina era terrivel porque eram crianças que vinham da sarjeta, [...] mas só se aceitava filhos de familias legitimamente constituidas [...] Na vila, a vida é difícil [...] pois então se começou a aceitar somente com oito ou nove anos, para não trazerem muitos vícios [...]. Isto ajudou a equilibrar [...] só que o regime era

28 A categoria lugar, enquanto um espaço construído num dado tempo e a sua dimensão educativa, é analisada no estudo de FRAGO, Antônio Vinao. "Del espacio escolar y la escuela como lugar: propuestas e questiones". In: Revista de Histónia de la Educación, Salamanca, Ediciones Univesidad de Salamanca, $n^{2} 12-13,1993-94$. Dentre os autores que desenvolveram estudos importantes com base no controle do tempo e/ou do espaço como meio de "formação" menciona-se também Edward Thompson e André Petitat.

29 Ver GOFFMANN, Erving. Manicômios, prisōes e conventos. São Paulo. Editora Perspectiva, 1974.

30 BOURDEU, P. Réponses - pour une anthoropologie réflexive. Paris, Éditions du Seuil, 1992, p. 103. 
muito rigoroso: não saíam todo o ano, não tinham férias do internato [...] Para manter a disciplina havia castigos: ficar de pé, dar voltas no pátio, ficar fora do time de futebol.

Apesar do reduzido espaço para as iniciativas e decisões do interno, a possibilidade de interagir sempre existiu, permeando as relações que ele estabelecia com os demais membros do ORFANOTROFIO. Sendo assim, o órfão como qualquer agente social, constituiu-se nas relações de certa forma já definidas também nas suas tomadas de posição, face às constantes lutas pelo poder que permearam o PÃO DOS POBRES.

Por isso, na relação com os seus superiores, o interno foi também cúmplice na constituição desse "novo homem". O relato ${ }^{31}$ de um ex-interno, é um bom exemplo de como os meninos também tiravam partido das disputas com os seus superiores:

"Um outro foi o que aconteceu com o Antônio Krieger. O Irmão vivia pegando o pé dele e um dia no refeitório deu uns tapas nele, arrodeou-o pela mão e acabou jogando-o em cima de um balaio de pães. Quando ele caiu sobre o balaio ainda teve tempo de pegar um pão sem o Irmão ver, foi a forra dele. Ele apanhou, mas saiu com dois pães e os outros ficaram só com um".

Ser disciplinado quase todo o tempo e em todos os espaços trazia também algumas vantagens:

"Nas festas de Santo Antônio ou de São João B. de La Salle, eu tinha o privilégio de trabalhar como garçom. Aproveitava para comer bem e até para guardar algumas coisinhas pra depois; guardava nas caixinhas vazias de marmelada que eu escondia".

A principal estratégia para instaurar uma formação integral era a de ocupar os internos e, mais do que isso, controlar a utilização do tempo, em todas as ações e espaços por onde ele andava. Os depoimentos a seguir fazem referência ao tratamento do tempo, nos vários espaços e atividades dos internos, que estava estipulado no Regulamento Interno.

"[... Havia horário para tudo. Para se ir ao banheiro, apenas para urinar, era indicado um local mais aberto, mais público. Se fosse no caso de defecar tinha que solicitar aos Irmãos a chave de um outro banheiro, pois essa era uma situação mais demorada e por isso mesmo mais controlada".

31 Os depoimentos mencionados nesse estudo referem-se às entrevistas realizadas com os ex-intemos do PÃO DOS POBRES, que ai permaneceram de 1930 a 1970 . É certo que as suas lembranças sobre os fatos vividos há tanto tempo não representam a mesma imagem que experimentaram na época do Orfanato: já não são mais os mesmos, sua percepção foi alterada e, com ela, suas idéias, seus juizos de realidade e de valor. Mesmo assim, a memória é uma expressão do seu relacionamento com o espaço institucional do PĀO DOS POBRES, no qual passaram vários anos de suas vidas; por isso, os registros são da maior importância - são a lembrança fazendo sobreviver o passado - para captar as principais caracteristicas e a extensão do processo, cujo objetivo era formar trabalhadores, dentro de um espirito cristão. Mais detalhes sobre a importância e o significado da memória In: HALBWACHS, Maurice. La mémore colletive. Paris, Édition PUF, 1950, dentre vários outros autores que abordam essa questão. 
0 tempo do dormitório mencionado no Regulamento, no Art. $15^{\circ}$ dizia que "o silêncio e a modestia são de rigor [...] durante as horas de descanso".

Os relatos dos ex-internos confirmam a maneira austera como era encarado o descanso.

"Não se podia nem se mexer. O Irmão passava com uma varinha de marmelo, ele controlava [...] e se pegava a gente se mexendo na cama dava com a varinha, aquilo dói!"

Mesmo com todo o controle, o interno encontrava uma maneira de se opor:

"[...] A senhora sabe que guri, a gente tem fome. Eu tinha no bidezinho, uns pães duros de quinze dias. Chegavam a ser verdes. Eu comia, quietinho, nunca me fez mal e a ninguém. Comia todo o pão como um ratinho. Às vezes, o Irmão pegou a gente".

O relato de um Irmão, que foi prefeito de disciplina na década de 50 , confirma o controle que o Regulamento previa para os tempos no espaço do Refeitório:

"[...] Quando eles iam para o refeitório, eles iam em fila militar, em silêncio, era tudo por sinal. O prefeito de disciplina tinha uma sineta, dava uma batida assim $e$, então, já sabiam que era o final do almoço. Então rezavam e saíam. O chefe de mesa reunia o material e levava para a copa. Além dessa, a sua função era a de cuidar se todos se serviam de forma igual, pra ninguém sair prejudicado".

O Regulamento também estipulava a utilização do tempo nos lugares de recreios. No artigo $28^{\circ}$ consta que "Os órfãos irão aos recreios em ordem e silêncio e aguardarão, enfileirados no pátio, o sinal de os começar". Art. 30: "Nunca se afastarão do lugar do recreio sem licença do Prefeito".

Sobre esse aspecto, um ex-interno disse:

"Os Irmãos tinham cuidado para que não se formassem panelinhas, amizades muito profundas, homossexualismo e outras coisas que, geralmente, ocorrem em internatos. Os grupos não podiam andar isolados pelos locais na escola; mantinham os alunos em constante ocupação; na hora da aula era verificado se todos estavam nas salas; na hora dos jogos todos tinham que participar, tinham que integrar o grupo em movimento com movimento".

É impressionante como foi forte essa exigência, que impunha aos internos o movimento constante nos vários espaços e tempos vividos por eles. Todos os entrevistados referiram-se a isto, parecendo representar algo que mobilizou suas vidas, mesmo após a época e fora do espaço do internato.

"[... Durante o intervalo das aulas na parte da manhã por volta das 9 h30 todos ficavam no pátio para brincar (corrida, futebol, etc). Só que todos deviam se mexer ninguém podia ficar parado. O Irmão usava um apito e se algo ocorresse mal durante o recreio ele apitava e todos eram obrigados a parar, viravam estátuas. Ele dominava". 
Sem dúvida, o ex-interno captou muito bem por que ele devia manter-se em movimento o tempo todo. Era que assim, outras dimensões, que não fossem as do internato, tinham pouquíssimas chances de se instalarem, integrando ou inibindo o novo sistema de disposições que o processo estava implantando. Afinal, tal estratégia pretendia neutralizar tudo o que significasse alguma ameaça ao sistema, organizado para produzir o "novo homem".

Vários tempos do interno eram vividos no pátio, mas todos eles eram devidamente controlados, para que fossem ocupados conforme prescrevia o Regulamento.

As oportunidades para circular fora do espaço do Orfanotrófio eram bastante raras, apenas ocasiões especiais, em que, igualmente, as ações e os comportamentos determinados pelo Regulamento eram atentamente observados. É o caso de excursões, idas ao circo, nos desfiles da Semana da Pátria, procissões, visitas às autoridades, festas religiosas e jogos de futebol em outras instituições, onde a ordem era "falar a meia voz", não abandonar o grupo e nem "olhar pelas portas e janelas das casas".

No final da década de 50 e no decorrer dos anos 60, os vários momentos em que os internos estavam realizando uma atividade recreativa e foram fotografados, revelam que nessas ocasiões, apesar do Regulamento, existia um clima de maior descontração entre os internos e com os próprios Irmãos.

O tempo dedicado às artes, que representou para o órfão a oportunidade de contactar com situações externas ao espaço do Orfanato, era também disciplinado; as atividades de teatro, banda ou coral eram supervisionadas ou dirigidas por um Irmão, com uma hora marcada na rotina diária.

As recomendações sobre o tempo do interno, com seus familiares ou responsáveis, eram bem detalhados no Regulamento, a ponto de se prever dia, local e tempo limitados para as visitas.

A interação do interno com outros agentes sociais dava-se, ainda, em festas: a de Santo Antônio, o Natal, as formaturas, as apresentações em homenagem à Semana da Pátria e aos benfeitores. Estes eram as pessoas que mais circulavam no espaço do PÃO DOS POBRES, afora os Irmãos, os órfãos e os funcionários da casa. Isso tinha um objetivo: legitimar o poder dos benfeitores, através do poder que essa obra de caridade estava significando no período, em especial até meados dos anos 60 .

Por isso, vários dos tempos, de cunho mais social, foram bem lembrados pelos ex-internos, e sempre associados à presença desses personagens - os benfeitores.

"[...] No Natal ou Páscoa as famílias nobres como os Chaves Barcelos, que eram benfeitores, podiam ir até lá fazer uma visitinha. No mais não entrava ninguém lá".

"[...] A minha madrinha era a Dona Ilda, uma benfeitora do Orfanato. Ela era quem escolhia um para ser seu afilhado; ela perguntava se eu havia me comportado, como eu ia indo nas aulas e no fim do ano dava presentes no Natal. Havia também outros benfeitores, os padrinhos, o Ildo Meneguetti, o Malvásio".

"[...] A festa de Santo Antônio era tradicional. Na Igreja tinham três dias de orações, mas no pátio era um dia só onde estouravam bombinhas, faziam fogueiras, etc. Nestas festas os Irmãos ficavam mais tolerantes mas sempre controlando tudo. Eles não aliviavam nunca. Tinha o casal festeiro que organizava essa festa e os es- 
colhidos eram sempre da alta sociedade. Muitos benfeitores marcavam a sua presença nesses festejos".

"[...] Na festa de 15 de agosto, festa de São Roque, um benfeitor da Instituição é que dava o churrasco. Tinha missa, apresentação da banda, jogos, etc; era uma solenidade. O Rafael Malvársio era quem doava esse churrasco".

Um espaço que ocupava um tempo considerável da rotina diária vivida pelo interno, era o da Igreja, um lugar em que se pressupunha, conforme ditava o Regulamento, "uma postura impecável".

"[...] Havia missas todos os dias; no Domingo eram duas missas, uma às 7 horas e outra às 9 horas (essa era mais festiva), onde havia a participação da comunidade. A religiosidade dentro do PÃO DOS POBRES era algo muito forte, tanto que eu era para ser padre".

"[...] Havia muitas missas e eu sempre freqüentava porque meus parentes e meus vizinhos também freqüentavam. Era então um ponto de encontro onde eu podia vê-los".

"[...] Fundei a JOC dentro do PÃO DOS POBRES, juntamente com os Irmãos para transmitir a mensagem social cristão para os alunos".

"[...] Fui coroinha durante muitos anos".

"[...] Fui presidente da Juventude Católica, eram escolhidos os presidentes como na maçonaria, convidados".

"[...] Participei da Congregação do Menino Jesus quando estava' na turma dos menores e, depois, quando entrei para a oficina, fui congregado mariano".

Parte do tempo do interno era dedicado à sua aparência ou a cuidados de ordem física: limpeza do corpo e das roupas, tratamento de doenças ou de problemas por acidentes.

Para que todos esses tempos fossem cumpridos nos espaços previamente indicados, segundo o Regulamento e de acordo com a maneira de cada responsável interpretá-lo e aplicá-lo - desde o Ir. Diretor até o interno chefe de equipe - as punições para o não-cumprimento podiam ser da repressão feita em particular, as baixas notas em disciplina até a expulsão definitiva do órfão.

Uma das constantes nos depoimentos dos ex-internos é a memória da repressão física, utilizada pelos Irmãos, quando eles julgavam inadequadas as atitudes dos internos, mesmo se não estava prevista no Regulamento. ${ }^{32}$ Os depoimentos diferenciam-se quanto à intensidade da agressão e sugerem que ela se tornou mais branda, a partir da década de 60. Mas todos os internos têm as suas histórias para contar sobre o tempo vivido no espaço do Orfanotrófio, quando o tema é castigo; alguns relatam com veemência, procuram contudo camuflar a indignação:

- O Irmão prefeito era muito violento; muita surra apanhei dele; muita bolacha no rosto eu levei; eu ficava arrasado, mas não tinha nada o que fazer e ninguém

32 Observa-se que, sob determinadas condições, La Salle permitiu o uso da vara e da férula. Dizia que se deve dar um e, no máximo, dois golpes com a férula e somente o Irmão autorizado pelo diretor poderia ter uma vara na aula. In: JUSTO, Ir. Henquieu. La Salle - O patrono do magistério. Porto Alegre, Livraria Santo Antônio, 1961, p. 193. 
para desabafar ou pedir proteção; fiquei marcado por muito tempo depois. Era o suficiente rir ou cochichar na fila para ser repreendido e até mesmo agredido fisicamente com pontapés.

- Eu era rebelde e recebia muitos castigos. Um deles foi não participar de um piquenique na Pedra Redonda. Eu fiquei muito marcado, visado. Isso tudo já na turma dos maiores. [...] Vários foram os castigos: correr cinqüenta voltas em torno do pátio "limpíssimo" e recolher cinqüenta peças (sujeiras); davam fortes empurrões na gente; puxavam a orelha; pegavam pelos cabelos; davam bofetadas na cara. Era sopapo na cara que entortava a cara para o outro lado; aqueles monstrengos, com aquelas mãos.

[...] O Irmão usava batina e no bolso ele tinha um cinto. Quando um aluno conversava em aula, ele dava umas duas lambadas nas costas do aluno.

[...] Certa vez fiquei durante três meses num canto olhando para a parede. $O$ pessoal saía da aula e ia pro pátio brincar e eu ia pro castigo. Não devo ter feito algo muito grave pois nem me lembro o que fiz.

- O principal castigo, quando eu entrei, era ficar interno permanentemente, não sair para a rua, nem no período de férias. Constituia-se no principal castigo pois eu considerava aquilo uma prisão. Certa vez ganhei um tapa do Irmão Arsênio porque o Irmão pensou que eu havia feito uma certa brincadeira na fila. Foi o castigo mais grave que eu lembro ter recebido. Outra forma de castigar era raspar o cabelo.

\section{3 - Algumas considerações finais}

A trajetória da formação instaurada no PÃO DOS POBRES esteve associada ao aprofundamento de uma nova pedagogia, proposta e executada por membros da Igreja Católica. Iniciou com o ABRIGO 1895, depois transformado em ORFANOTRÓFIO (1916) onde já havia ensinamentos rudimentares sobre alguns ofícios, e se desenvolveu até a instalação das oficinas que deram origem ao Liceu de Artes e Ofício, após 1930.

Assim, dadas as condições referidas anteriormente com destaque ao rigor com que o espaço e o tempo eram controlados no decorrer do processo, o interno do PÃO DOS POBRES incorporou um novo habitus, construído na relação com os demais agentes sociais. Foi também através desse sistema de disposições - o habitus - mais ou menos ajustado às posições dos internos, que se realizaram as possibilidades nelas inscritas. ${ }^{33} \mathrm{Em}$ função disso, é possível dizer que o ex-interno do Orfanotrófio constituiu-se num "produto da história, da história de todo o campo social e da experiência acumulada através de uma trajetória determinada dentro do subcampo": o PÃO DOS POBRES, enquanto uma esfera do campo religioso.

Vale lembrar que as condições favoráveis à instauração do habitus encontramse no ambiente familiar ou em regimes de internato. As disposições definidoras do habitus são incorporadas, em sua grande maioria, na infância. Porém não são imu-

33 BOURDIEU, P. "Le Champ littéraire". In: Revue Actes de la Recherche en Sciences Sociales. Paris, Éditions de Minuit, $n^{2}$ 89, Sept/1991, p. 36. 
táveis no tempo, podendo mudar em função das experiências a que os agentes são expostos. Em outros termos, "o habitus é durável, mas não imutável" ${ }^{34}$

Foi através de um ritmo imposto para a realização das várias atividades indicadas ao órfão interno, as quais ocupavam todos os tempos da sua rotina e com a delimitação prévia e restrita do espaço, que a formação nessa obra assistencial conduzida por representantes da Igreja Católica - ao mesmo tempo que imprimiu uma forma que representou limites ao desenvolvimento do interno enquanto um ser integral, instaurou alguma competência ("saber-ser") ${ }^{35}$ junto a esse futuro trabaIhador.

Alguns depoimentos dos formados por essa escola de ofício, hoje aposentados confirmam isso:

[...] Sai do Pão dos Pobres como marcineiro. Trabalhei de instrutor na Secretaria de Educação. Fui cedido durante 25 anos à marcenaria do próprio Pão dos Pobres; estive também na escola Parobé. Trabalhei também na marcenaria da Febem...

[...] Trabalhei numa tipografia na Rua Dr. Timóteo/Porto Alegre. Trabalhei sete anos no Banco Nacional do Comércio, e, durante 25 anos, no Banco do Brasil, concursado na minha profissão.

[...] Depois de formado, trabalhei na oficina. Pouco tempo depois passei a chefe de torno, depois da oficina geral e fui gerente técnico. Ao sair daí, fui trabalhar de gerente técnico de uma empresa.

Tais considerações evidenciam que as disposições gerais (estruturais estruturadas e estruturantes) que constituem a formação em escolas de ofício católicas, operacionalizam-se e são incorporadas através de um conjunto de práticas e ações, com os seus tempos e os seus espaços bem definidos e controlados, os quais são assegurados por um jogo de relações de poder entre os vários agentes sociais envolvidos nesse processo: do campo religioso e dos demais campos que constituem o espaço social, especialmente com o campo do poder.

${ }^{34}$ BOURDIEU, op. cit., p. 109 (1992).

35 A competência é entendida aqui como a capacidade de o indivíduo integrar os conhecimentos de maneira eficaz sobre objetos de açőes. In: GLLET, Pierre (org.). Construire la formation. Paris. Éditions E.S.P., 1991, p. 72. 